\title{
UK postgraduate medicine examinations: opportunities for international candidates
}

\author{
Authors: Lawrence McAlpine, ${ }^{A}$ Elona Selamaj, ${ }^{B}$ Colleen Shannon, ${ }^{C}$ Liliana Chis, ${ }^{D}$ Jane Dacre ${ }^{E}$ and Andrew Elder ${ }^{\mathrm{F}}$
}

\section{The medical profession is global, and ambitious trainee physicians around the world are eager to attain internationally recognised postgraduate medical qualifications. The MRCP(UK) and specialty certificate examinations of the Federation of Royal Colleges of Physicians of the United Kingdom provide such qualifications, and between 2002 and 2013, the number of international candidates attempting these examinations grew substantially. Delivering these proven and reliable UK-based examinations in other countries has many local benefits: it enhances careers, strengthens medical training and improves standards of patient care. In collaboration with international colleagues, the Federation is committed to continued growth that extends these benefits to all physicians, wherever they work and live.}

KEYWORDS: Specialty certificate examination, Part 2 clinical examination (PACES), Royal College of Physicians' examinations, international postgraduate medicine examinations, MRCP(UK) examination

\section{Introduction}

As medicine has become a truly global profession, it has also become ever more competitive. Ambitious young physicians seek ways to demonstrate their knowledge and clinical skills with internationally recognised qualifications, and many choose to take the postgraduate medical examinations offered by the Federation of Royal Colleges of Physicians of the United Kingdom. These include the three parts of the MRCP(UK) diploma examination, 'the membership', and 12 specialty certificate examinations (SCEs), each of which is a defining academic achievement in a physician's career. This short review describes the examinations on offer internationally from the Federation of Royal Colleges of Physicians of the UK, explains their development and explores their future.

Authors: ${ }^{A}$ international associate medical director, MRCP(UK), London, UK; B senior examinations administrator, MRCP(UK), London, UK; Cfreelance medical writer, London, UK; Dhead of

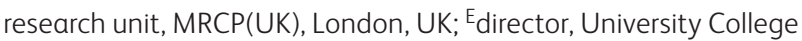
London Medical School, London and president, Royal College of Physicians, London, UK; Fmedical director, MRCP(UK), London, UK

\section{The examinations}

The current MRCP(UK) diploma examination (see www.mrcpuk. org/mrcpuk-examinations) consists of three parts: two written knowledge-based assessments (KBAs) in a multiple-choice, best-of-five (BOF) format (Parts 1 and 2 written) and a clinical skills component (Part 2 clinical examination [PACES]). ${ }^{1}$ The

SCEs comprise 12 different specialty examinations, each taking the form of a KBA in a multiple-choice, BOF format. ${ }^{2}$ The $\mathrm{MRCP}(\mathrm{UK})$ diploma is based on the UK curriculum for core medical training, ${ }^{3}$ and each SCE is based on the relevant UK specialty curriculum. (SCEs are offered for: acute medicine, dermatology, endocrinology and diabetes, gastroenterology, geriatric medicine, infectious diseases, medical oncology, nephrology, neurology, palliative medicine, respiratory medicine and rheumatology.)

All candidates who pass the $\mathrm{MRCP}(\mathrm{UK})$ diploma are entitled to use the postnominal MRCP(UK). However, only those who have completed a UK training programme in a specialty and passed the relevant SCE may adopt the postnominal $\operatorname{MRCP}(\mathrm{UK})$ (specialty).

\section{Place in the UK and international training}

Postgraduate medical training in the UK is clearly structured and regulated, with highly developed curricula ${ }^{3}$ and a range of workplace and summative assessments that are blueprinted (closely matched) to those curricula. In the UK, completion of the MRCP(UK) diploma is a mandatory component of core medical training. All three parts of the examination must be completed before a trainee can progress to specialty training. The SCE is also mandatory and must be passed before a trainee is awarded a certificate of completion of training (CCT) in the specialty.

In countries other than the UK, postgraduate medical training varies considerably in structure, regulation and development. Some systems have parallels with the UK and others with North American training models. Some countries require completion of the MRCP(UK) examinations as a part of internal medicine training (eg Hong Kong). Many other countries mandate their own national or regional curricula and assessments, while recognising UK examinations such as the MRCP(UK) for employment and recruitment purposes at the level of specialist trainee and above. 
Although there is increasing international demand for physicians in all specialties, the numbers of formal training posts in internal medicine remain limited in many countries. Structured training opportunities can therefore be highly competitive and difficult to access, and many medical trainees consequently follow relatively unstructured or self-designed training programmes. Furthermore, as competition and opportunity are highly variable, many individuals move away from their home countries to seek improved educational or employment prospects. Historically, many trainees migrated to the UK for such reasons. However, since 2006 a new immigration policy has severely restricted access to UK training for international medical graduates qualifying outside the European Economic Area. ${ }^{4}$

For trainees around the world, the appeal of MRCP(UK) examinations relates to their recognised high standard and mandatory place in UK training. ${ }^{5}$ By passing the membership, international trainees can benchmark their own knowledge and clinical skills in an explicit manner. In addition, the MRCP(UK) diploma continues to place emphasis on the core bedside clinical skills of history taking and physical examination, which, despite their continuing value in clinical practice, are not similarly emphasised in all other postgraduate assessment systems. MRCP(UK) examinations may also appeal to international candidates because the entry criteria are essentially experiential and not dependent on enrolment or appointment into a specified training programme. A trainee may sit Part 1 of the MRCP(UK) 12 months after the primary medical qualification has been obtained. Once they have passed Part 1, candidates are eligible to attempt the Part 2 written and clinical examinations in any order. ${ }^{6}$ The SCEs are open to trainees with any prior level of medical experience, and completion of the MRCP(UK) diploma is no longer a prerequisite. ${ }^{7}$

The MRCP(UK) examinations therefore offer an accessible and exportable set of qualifications, which demonstrate a high level of knowledge and clinical skill relevant to the practice of internal medicine. International trainees may attain these qualifications irrespective of their access to accredited training programmes and without the need to move to another country.

\section{Internationalisation of MRCP(UK) - a brief history}

The first iteration of the current membership examination can be traced back 150 years, to the MRCP London examination launched in 1859. The Royal College of Physicians of Edinburgh followed with its own membership examination in 1881, and the Royal College of Physicians and Surgeons of Glasgow instituted an examination for fellows in $1886 .{ }^{7}$ In 1968 , the three colleges united to deliver the $\operatorname{MRCP}(\mathrm{UK})$ examination.

International graduates have come from countries outside the UK to sit membership examinations since the early 1900s - the Edinburgh College examination register records a graduate from Madras (now Chennai) passing the membership in Edinburgh in 1907. In the years since, increasing numbers of trainees have come to the UK, some with the intention of undergoing training, completing examinations and then obtaining longterm employment, but some simply to sit examinations before returning to clinical practice in their countries of residence.

Membership examinations were first delivered outside the UK during World War II, primarily to serve UK medical graduates stationed internationally, eg in Poona, India. Although formal records are not available to us, we understand that local graduates did also access the examination at that time. It was not until 1972 that a structured programme of delivery outside the UK was commenced, with the Part 1 written examination delivered in Egypt for the first time. Since then the Federation of Royal Colleges of Physicians of the UK have steadily developed the delivery of the examination outside the UK.

\section{Recent activity data}

The countries in which the various examinations can be sat in 2014 are shown in Figs 1 and 2. The SCEs are computer based

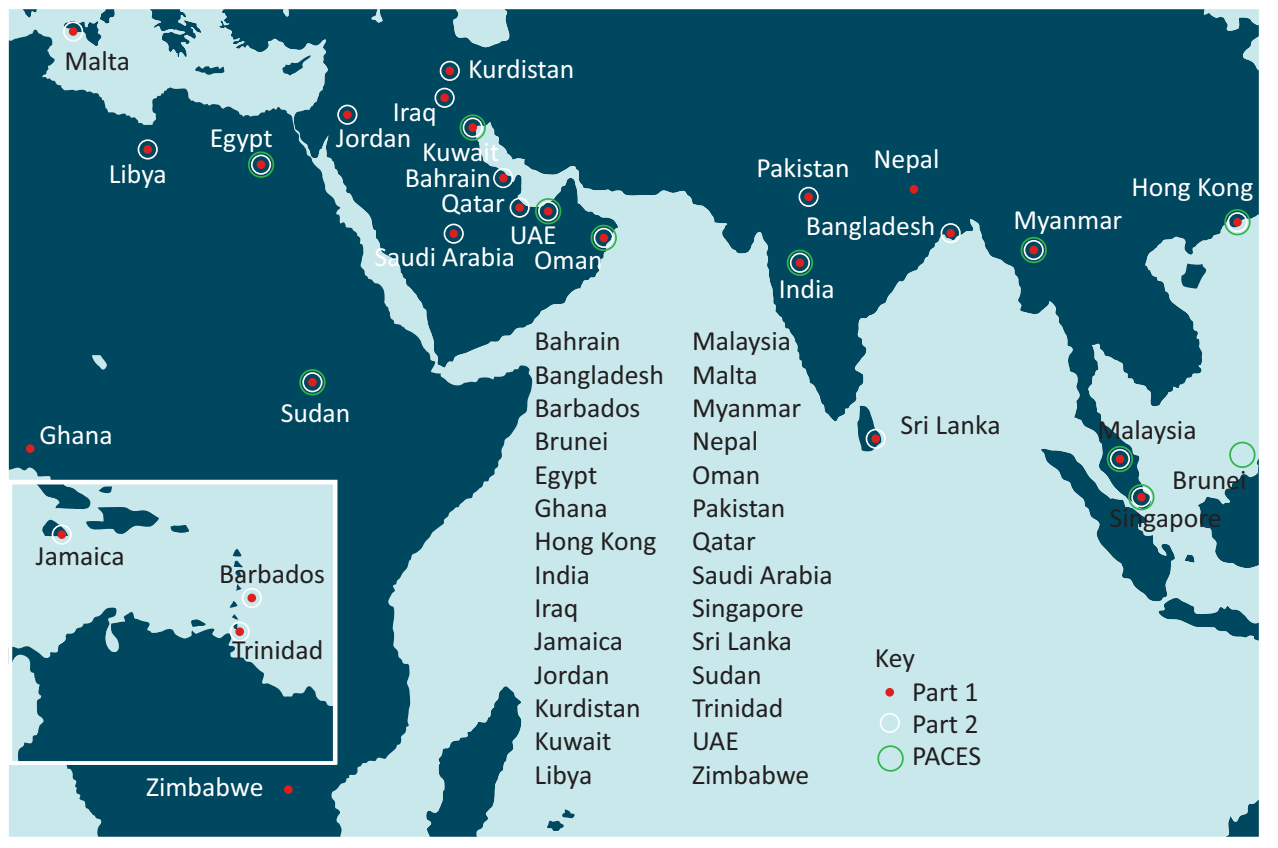

Fig 1. Countries where MRCP(UK) examinations are taken outside the UK. 


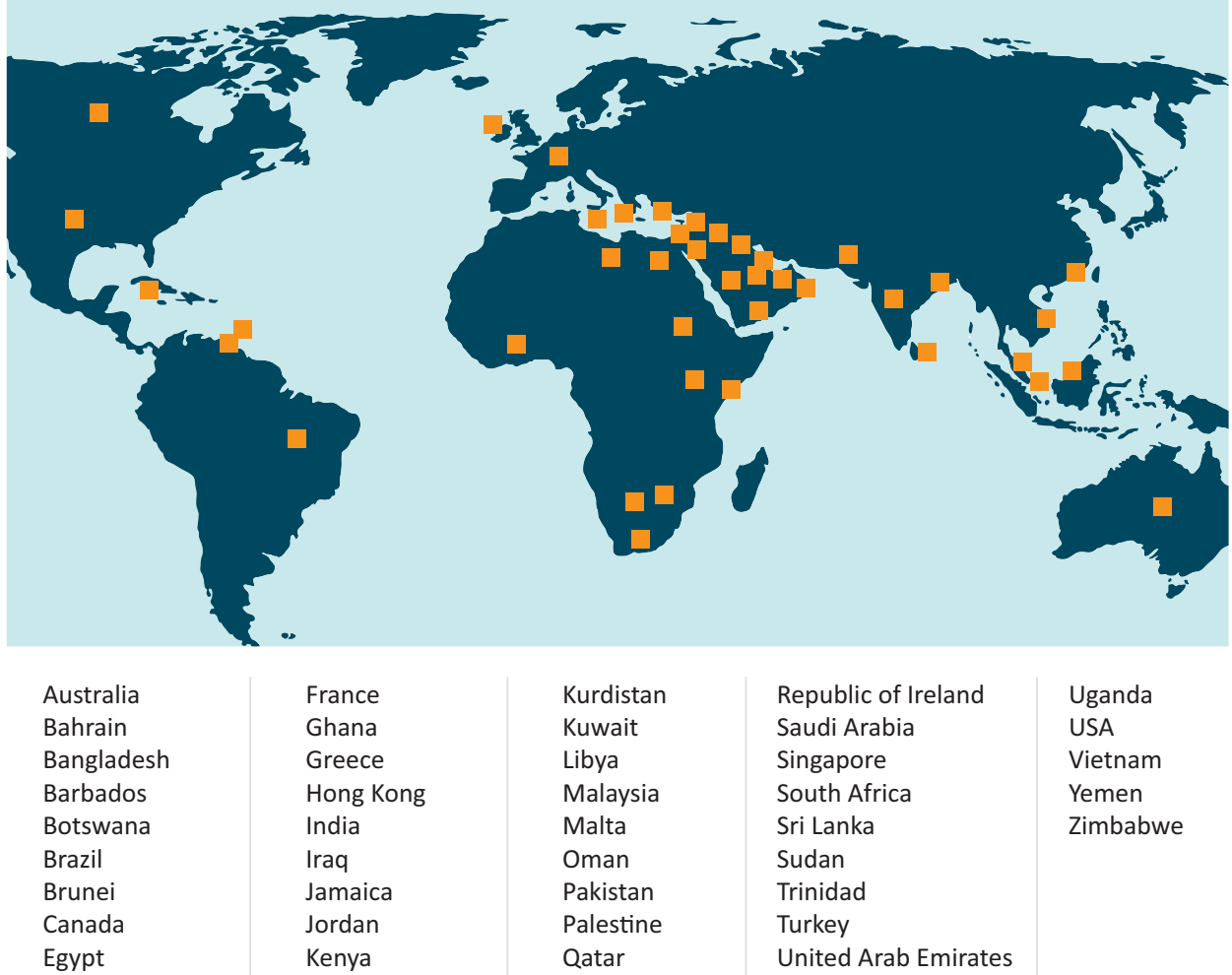

2. Countries where specialty are taken outside the UK.

Egypt

and delivered by a large company with a global presence. In principle, therefore, the SCEs can be offered in any country. For the MRCP(UK) diploma, Parts 1 and 2 written are paper based, and PACES is hosted in clinical centres.

Candidate numbers in these centres have steadily risen since the start of this century and the balance between UK and nonUK delivery has changed significantly, especially since the new immigration rules came into force. Almost all candidates in non-UK centres are international medical graduates (IMGs), but a few UK graduates (UKGs) sit the examinations outside the UK for a variety of reasons. Between 2002 and 2013, the number of candidates attempting Part 1, Part 2 written and PACES in centres outside the UK increased by $200 \%, 320 \%$ and $217 \%$, respectively (Fig 3). Over the past 5 years, 33,393 attempts at the various parts of the MRCP(UK) examination

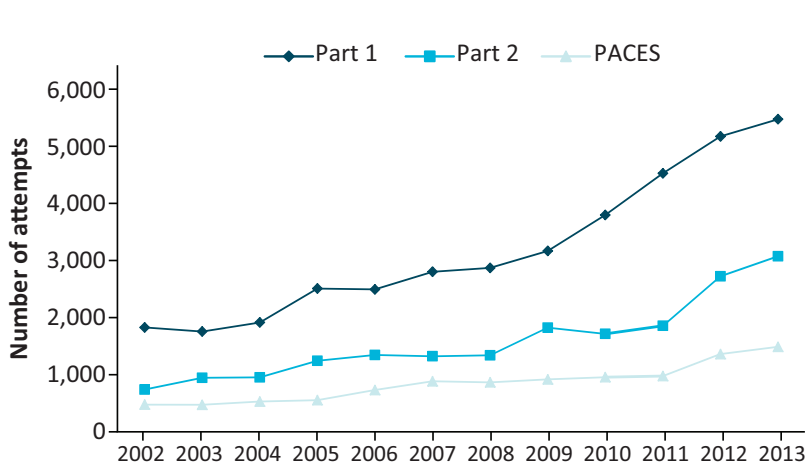

Fig 3. Part 1, Part 2 and PACES attempts, international centres, 2002-13. have been made in international centres. In 2013, for the first time, the number of candidates sitting Part 1 outside the UK was greater than the number sitting in the UK. Demand for the newer SCEs over this period grew by $243 \%$, from 140 attempts outside the UK in 2011 to 481 attempts in 2013. A total of 1,115 candidates have attempted the SCE in 33 countries outside the UK since their inception.

The comparative numbers of IMGs and UKGs sitting the MRCP(UK) diploma and SCEs are shown in Fig 4, with more details appearing in Figs 5 and 6. In all examinations, more

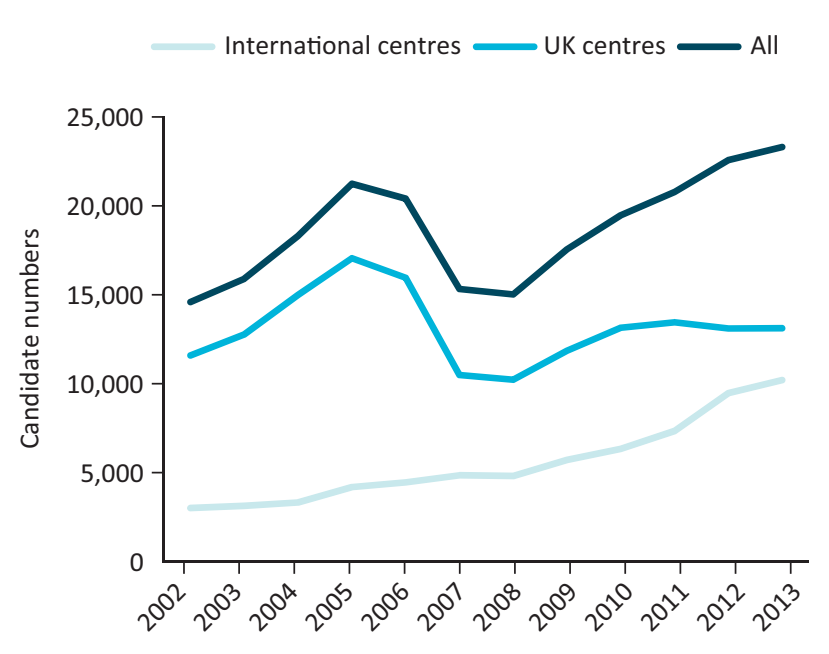

Fig 4. MRCP(UK) diploma and specialty certificate examination (SCE): global attempts 2002-13. 

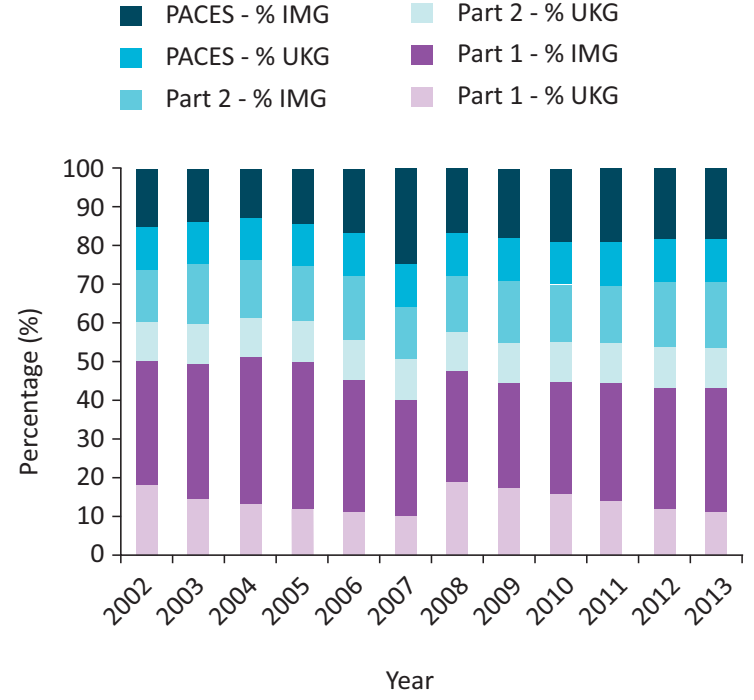

Fig 5. MRCP(UK) examinations - sitting candidates: percentage by graduation type and examination type. IMGs = international medical graduates; UKG = UK graduates.

candidates are IMGs than UKGs. Many IMGs continue to migrate to the UK to train, work and live and, because the availability of PACES outside the UK does not yet fully meet the demand, some IMG candidates still come to the UK with the sole purpose of sitting this examination.

\section{The examinations in Europe}

A variety of qualifications in internal medicine exist in non-UK EEA countries. Historically, interest in the MRCP(UK) for non-UK EEA graduates has been relatively low, other than for those who migrate to the UK for training or employment purposes. In 2004 a joint initiative to deliver a European diploma in internal medicine was piloted with the European Federation in Internal Medicine, but trainee interest was very low and the examination no longer takes place.

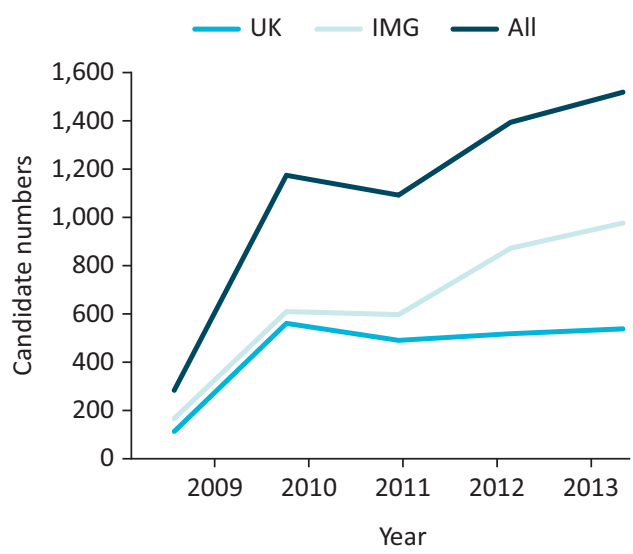

Fig 6. Specialty certificate examination (SCE): attempts, UK and international medical graduates (IMGs), 2009-13.
However, the recent development of the SCE has generated new interest in Europe. In 2013, a 2-year pathfinder project was established to explore demand for a pan-European specialist examination in gastroenterology, in partnership with the British Society of Gastroenterology and the European Board of Gastroenterology and Hepatology.

\section{Benefits of the international examinations}

Extending access to UK-based examinations to international centres brings benefits to trainees, the profession of medicine in the UK and other countries, and ultimately to patients in many parts of the world. In routine candidate surveys conducted after MRCP(UK) examinations, international candidates have noted that preparing for a major international examination adds breadth to a physician's training. It provides a new perspective, along with an opportunity to reflect on their knowledge, their training to date and the basis of their clinical practice. Success in the examinations is also regarded as an affirmation of professional achievement and remains a source of considerable personal pride. Pass rates in benchmark international qualifications have also been used as a means of determining the efficacy of educational interventions outside the UK. ${ }^{8}$

PACES remains an assessment of core bedside skills in medicine ${ }^{9}$ and its delivery requires close involvement of local physicians in many countries and the participation of patients from a wide range of backgrounds to ensure relevance to the candidate's everyday experience in the workplace. Senior UK physicians continue to form part of the team of 10 examiners that delivers each PACES examination, and professional and collegiate relationships are fostered by such contacts. Working together on examinations can yield other benefits, including shared opportunities for international collaboration in educational and research projects.

Working as a PACES examiner or MRCP(UK) question writer also offers valuable continuing professional development opportunities to physicians around the world, and many benefit from the well-established training programmes, resources and support services provided.

Although there are many positive reasons to offer the examinations internationally, there are inevitably challenges and controversies. The Federation always aims to address these in a transparent and evidence-based manner with significant commitments to research, and through a process of continual dialogue and improvement.

\section{Differential attainment}

Routine analyses of pass rates over many years have demonstrated that, in general, IMGs perform less well than UK medical graduates in all components of the $\mathrm{MRCP}(\mathrm{UK})$ and the newer SCEs. MRCP(UK) has published information about this observation ${ }^{10}$ and has in addition noted that performance is also associated with the UK medical school of graduation. ${ }^{11}$

Prior educational attainment, combined with teaching, training and experience in both the undergraduate and early postgraduate years, is thought to account for these differences, in both UK and international graduates. Concerns that subjective bias might account for differential attainment in PACES have not been supported by detailed published analysis, ${ }^{12}$ but linguistic and cultural elements of 


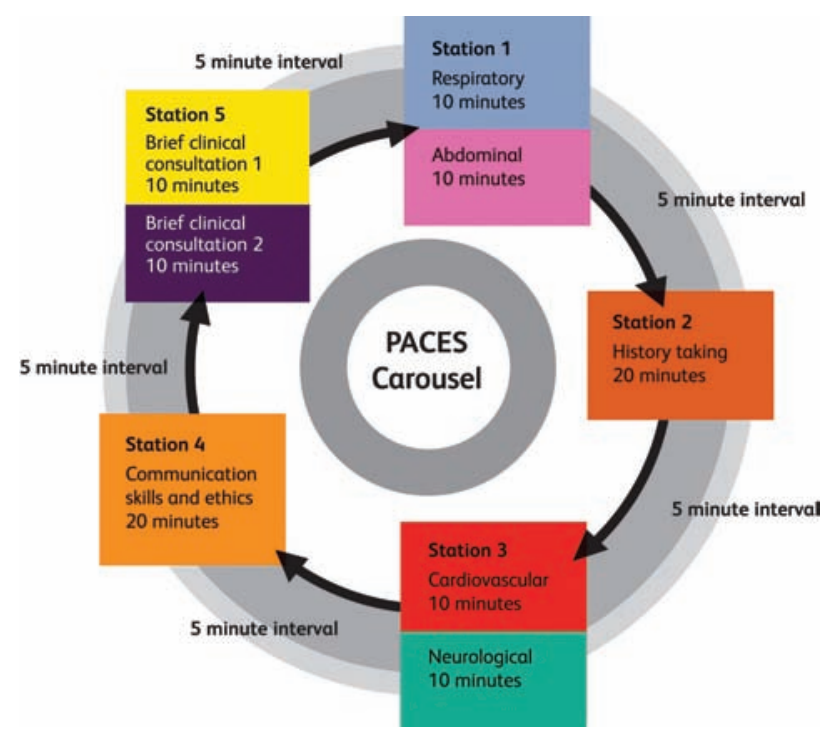

Fig 7. PACES (Part 2 clinical examination) carousel.

communication could make the required standard harder to attain for some IMGs.

$\operatorname{MRCP}(\mathrm{UK})$ has been at the forefront of research into this phenomenon and aims to identify any element of assessment that unreasonably disadvantages a candidate from any background, while maintaining the overall high standard for all parts of the examination.

\section{Meeting demand}

In 2013, for the first time, the total number of candidates attempting the $\mathrm{MRCP}(\mathrm{UK})$ Part 1 written examination in centres outside the UK exceeded the number sitting in the UK. Developing and maintaining the content for all of the examinations requires significant resources, as does the provision of candidate services. However, the Part 1 and Part 2 written examinations are fairly straightforward to deliver on the day and, when they move to a computer-based delivery platform similar to the SCEs, there will be no theoretical limit to the range or capacity of these examinations.

As a result of its unique emphasis on bedside skills in a clinical setting, PACES is a more challenging examination to deliver internationally. The basic examination cycle is shown in Fig 7; each day of examining requires 10 expert assessors as clinical examiners, around 20 real patients, 2-4 surrogate patients and a range of ancillary and administrative staff. Examination facilities must be adequate and patient recruitment must be coordinated to a high standard.

Using the current delivery model, in which a maximum of 15 candidates can be examined in 1 day, 109 days of examining at international centres took place in 2013. This figure is a $35 \%$ increase on the previous year but, despite this expansion, demand for places still exceeded supply in several areas. In addition, as five of the 10 examiners travel from the UK to each international centre, around 150 such examiners were required to deliver the examination outside the UK in 2013. Escalating demands on NHS consultants' time may limit the capacity to extend delivery to the levels required, as a growing number of candidates pass Part 1 and become eligible to attempt PACES. The alternative - that candidates travel to the UK to sit PACES - poses other challenges. The Federation remains committed to increased delivery and aims to make all of its examinations, including PACES, accessible to any physician wishing to attempt them, in any part of the world.

\section{The language of teaching and assessment}

Medical education in many countries outside the UK continues to be delivered in the English language and international students frequently study English language textbooks.

However, real-life clinical contacts with patients obviously take place in many other languages. Not infrequently, the doctor will not be able to speak the language or dialect of all patients whom they treat.

The MRCP(UK) written examinations and SCEs are all taken in English and PACES is also conducted in English. MRCP(UK) recommends, but does not mandate, spoken English proficiency at level 7.5 of the International English Language Testing System (IELTS) for candidates intending to sit the examinations.

Were $\mathrm{MRCP}(\mathrm{UK})$ to translate written examinations into languages other than English, it would be likely that entry to the examinations would increase further. However, were PACES to be conducted in the language in which each candidate prefers to practise, this would necessitate development of a totally new model of assessment for the clinical skills examination, including the loss of assessment by visiting UK examiners. At present, this component of the assessment is still regarded as valuable in non-UK centres and there is therefore no current plan for such changes.

\section{Content and country}

The MRCP(UK) diploma and SCEs are based closely on the relevant UK curricula, reflecting their primary role as mandatory assessments for UK trainees in internal medicine. Although there is clear overlap between the UK and other curricula, particularly in core clinical skills, the pattern of disease encountered in different countries might suggest that varying emphasis should be given to alternative content areas in different parts of the world. ${ }^{13,14}$ Local patients with conditions reflecting local morbidity do participate in PACES, and the core clinical skills that PACES is designed to assess, are therefore covered in the context of presentations and diseases that are highly prevalent in that locality. Significantly shifting the content of the written examinations would have implications for its recognition as a qualification for employment in the UK. It could also affect public perceptions of the examinations' overall standards. However, $\mathrm{MRCP}(\mathrm{UK})$ is exploring this issue in collaboration with international partners.

\section{Conclusion}

Postgraduate medical examinations offered by the Federation of Royal Colleges of Physicians of the UK provide strong professional credentials that are valued by physicians not only in the UK but also around the world, as evidenced by steadily growing demand. In our experience, delivering the examinations in partnership with our international colleagues 
can enhance the professional development of trainees and senior physicians in any country, while building local skills and capabilities on an organisational level as well. Securing patient safety and welfare is the ultimate aim of all medical education, and this is certainly true for the examinations, which encourage candidates to reflect on these issues as part of their preparation, and then assess their knowledge and professional judgement rigorously. We will continue working with our international partners to continue expanding access to the examinations, with the aim of making them accessible to all physicians who wish to aim for these respected qualifications.

\section{References}

1 Elder AT, McAlpine LG, Bateman N et al. Changing PACES Developments to the MRCP(UK) PACES examination. Clin Med 2011;11:231-4.

2 Mucklow J. Development and implementation of the specialty certificate examinations. Clin Med 2011;11:235-8.

3 Joint Royal Colleges of Physicians Training Board. Specialty training curriculum for core medical training. August 2009 (with amendments August 2013). London: JRCPTB, 2013. www.jrcptb. org.uk/trainingandcert/Documents/FINAL\%202009\%20 CMT\%20Curriculum\%20(AMENDMENTS\%20Aug\%202013). pdf [Accessed 27 August 2014].

4 Department of Health. Change to the immigration rules for postgraduate doctors and dentists (press release 7 March 2006). http://webarchive.nationalarchives.gov.uk/+/www.dh.gov.uk/en/ Managingyourorganisation/Workforce/Workforceplanningand development/InternationalrecruitmentNHSemployers/DH_ 4131259?PageOperation=email [Accessed 27 August 2014].

5 Membership of the Royal College of Physicians of the United Kingdom. Regulations and information for $M R C P(U K)$ candidates. London: MRCPUK, 2014. www.mrcpuk.org/mrcpuk-examinations/ regulations [Accessed 27 August 2014].
6 Membership of the Royal College of Physicians of the United Kingdom. Regulations and information for candidates for specialty certificate examinations. London: MRCPUK, 2014. www.mrcpuk. org/sites/default/files/documents/SCE_\%20Regulations_2014_0.pdf [Accessed 27 August 2014].

7 Vale A. International aspects. In: Cuthbertson L (ed), A concise history of the $M R C P(U K)$ examination: Celebrating 150 years. London: RCP, 2011;8-10.

8 Tariq M, Syed NA, Motiwala A et al. Effectiveness of educational interventions in improving clinical competence of residents in an internal medicine residency program in Pakistan. Education for Health 2011;24:573.

9 Elder A, McManus C, McAlpine L, Dacre J. What skills are tested in the new PACES examination? Ann Acad Med Singapore 2011;40:119-25.

10 Dewhurst NG, McManus IC, Mollon J et al. Performance in the MRCP(UK) Examination 2003-4: Analysis of pass rates of UK graduates in the Clinical Examination in relation to self-reported ethnicity and gender. BMC Med 2007;5:8.

11 McManus IC, Elder AT, de Champlain A et al. Graduates of different UK medical schools show substantial differences in performance on MRCP(UK) Part 1, Part 2 and PACES examinations. BMC Med 2008;6:5.

12 McManus IC, Elder AT, Dacre J. Investigating possible ethnicity and sex bias in clinical examiners: an analysis of data from the MRCP (UK) PACES and nPACES examinations. BMC Med Educ 13:103.

13 Devakumar D, Mandeville K. Should UK membership exams be held overseas? No. BMJ 2011;343:d4560.

14 Muir G, Thacker J. Should UK membership exams be held overseas? Yes. BMJ 2011;343:d4566.

Address for correspondence: Dr L McAlpine, International associate medical director, MRCP(UK), Royal College of Physicians, 11 St Andrews Place, Regent's Park, London NW1 4LE, UK

Email: Lawrence.McAlpine@lanarkshire.scot.nhs.uk

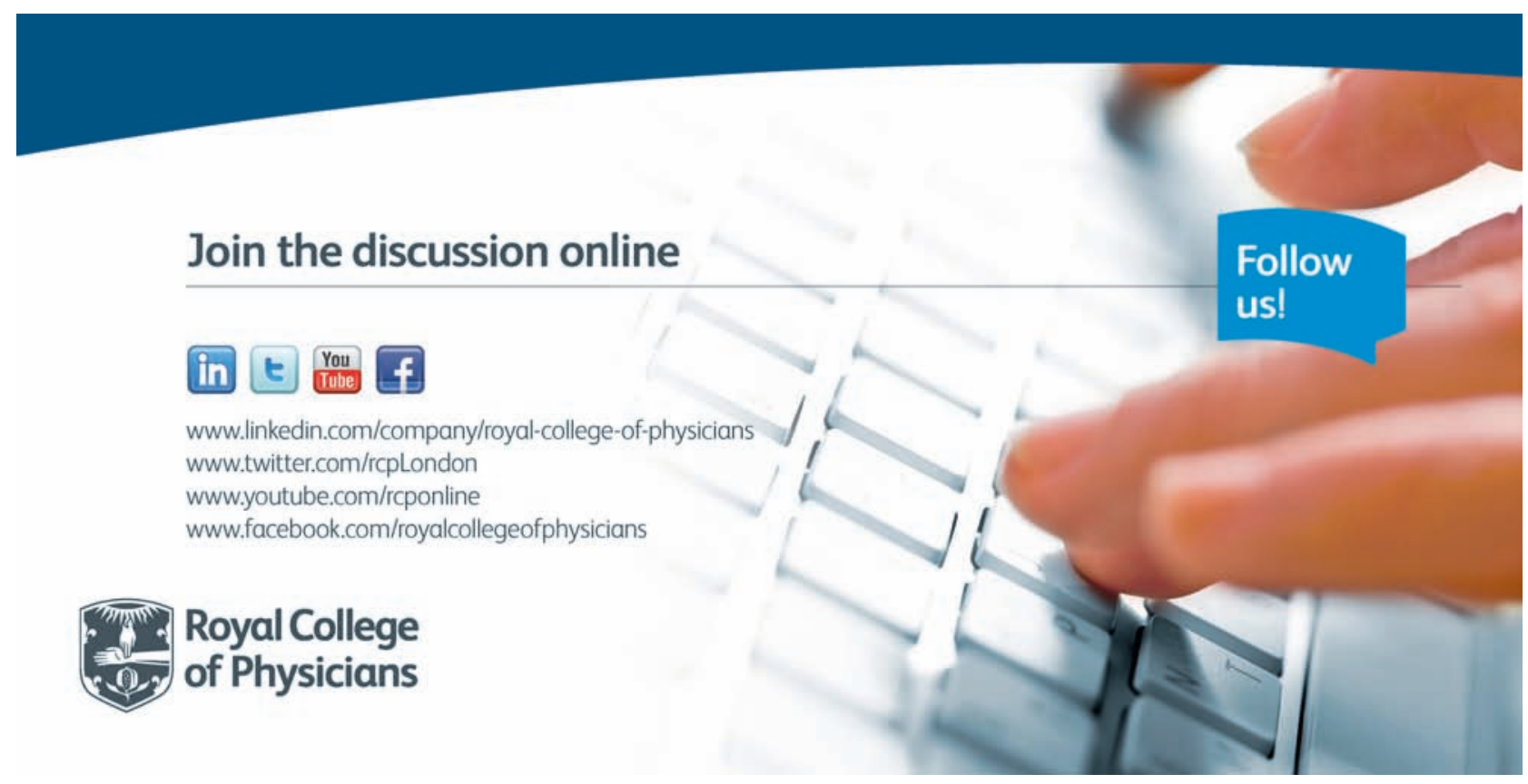

